\title{
TRÊS "PORQUÊS" A JURISDIÇÃO CONSTITUCIONAL BRASILEIRA DIANTE DO (APARENTE) CONFLITO ENTRE O MÍNIMO EXISTENCIAL E A RESERVA DO POSSÍVEL NA GARANTIA DOS DIREITOS FUNDAMENTAIS SOCIAIS E NO CONTROLE DE POLÍTICAS PÚBLICAS: HÁ MESMO ESCOLHAS TRÁGICAS?*
}

\author{
THREE "WHYS" TO THE BRAZILIAN CONSTITUTIONAL JURISDICTION IN \\ FACE OF THE (APPARENTLY) CONFLICT BETWEEN THE EXISTENTIAL \\ MINIMUM AND THE RESERVE OF THE POSSIBLE IN THE GUARANTEE OF \\ THE FUNDAMENTAL SOCIAL RIGHTS AND IN THE PUBLIC POLICIES \\ CONTROL: IS THERE REALLY TRAGIC CHOICES?
}

\section{Mônia Clarissa Hennig Leal ${ }^{1}$ Iuri Bolesina ${ }^{2}$}

\begin{abstract}
RESUMO - Este artigo tem por intenção aclarar que o conflito entre a teoria da reserva do possível e a teoria do mínimo existencial, no Brasil, é apenas aparente. Mira, ainda, apresentar três questões à jurisdição brasileira, sendo elas: "por que a jurisdição deve conhecer a Análise Econômica do Direito?", "por que a jurisdição deve estar atenta aos discursos (vazios) da reserva do possível?" e "por que a jurisdição deve priorizar o mínimo existencial?", todas no intuito de servirem como meio de reflexão ao julgador, notadamente quando da necessidade da prestação jurisdicional em casos que demandam alocação de recursos. Pretende-se, ao fim, com o auxílio do método dedutivo e do procedimento histórico-crítico, questionar se existem em face do mínimo existencial, escolhas "trágicas", mesmo diante da teoria da reserva do possível, na proteção e garantia de direitos fundamentais sociais e no controle de políticas públicas.
\end{abstract}

PALAVRAS-CHAVE: Jurisdição constitucional. Direitos fundamentais sociais. Análise econômica do direito. Reserva do possível x mínimo existencial. Escolhas tragicas.

ABSTRACT - This work is intended to explain that conflict between the theory of "the reserve of the possible" and the theory of existential minimum, in Brazil, is just apparent, in the way to not exist. It also aims submit three

\footnotetext{
1 Professora do Programa de Pós-Graduação em Direito - Mestrado e Doutorado da Universidade de Santa Cruz do Sul - UNISC, onde leciona as disciplinas de Jurisdição Constitucional e de Controle Jurisdicional de Políticas Públicas, respectivamente. Coordenadora do Grupo de Pesquisa "Jurisdição Constitucional aberta", vinculado e financiado pelo CNPq. Bolsista de produtividade em pesquisa do CNPq. Pós-Doutora em Direito pela Ruprecht-Karls Universität Heidelberg, Alemanha. Doutora em Direito pela Universidade do Vale do Rio dos Sinos - Unisinos, com pesquisa realizada junto à Ruprecht-Karls Universität Heidelberg, na Alemanha. E-mail: moniah@unisc.br.

2 Mestrando e Bolsista CAPES do Programa de Pós-graduação stricto sensu em Direitos Sociais e Políticas Públicas da Universidade de Santa Cruz do Sul - UNISC. Pós-graduando lato sensu em Direito Civil pelo Instituto Meridional de Educação - IMED. Membro do Grupo de Pesquisa Jurisdição Constitucional aberta: uma proposta de discussão da legitimidade e dos limites da jurisdição constitucional - instrumentos teóricos e práticos, vinculado ao CNPq e coordenado pela professora Drạ. Mônia Clarissa Hennig Leal. Advogado. E-mail: iuribolesina@gmail.com.
} 
questions to the Brazilian jurisdiction, as follows: "why the jurisdiction should know the Economic Analysis of Law?", "why the jurisdiction should be careful about (empty) speeches of "reserve of the possible"?" And "why jurisdiction should prioritize the existential minimum?", all in order to serve as a way of reflection to judge, especially when the judiciary need to decide on cases that require resource allocation. The aim is, with the end of this research, with the aid of the deductive method and procedure of the historical-critical, questioning if there is, in the face of existential minimum, tragic choices, even before the theory of "the reserve of the possible".

KEYWORDS: Constitutional jurisdiction. Fundamental rights. Law and economics. "Reserve of the possible" $x$ "existential minimum". Tragic choices.

\section{CONSIDERAÇÕES INICIAS}

A atuação do Poder Judiciário diante dos direitos fundamentais e das políticas públicas é questão sempre pulsante no cenário político-jurídico brasileiro contemporâneo. A questão perpassa, dentre outras argumentações, aspectos como escassez de recursos, custo dos direitos, assim como a afetação causada em diversos ramos da sociedade pelo agir - positivo - da jurisdição. No ponto final da confluência desses elementos há o que se convencionou chamar de "escolha trágica", a opção por uma situação em decorrência de outra(s) tão elementares quanto.

Também em volta desse tema há a proteção do mínimo existencial. Uma teoria jurídica reconhecida - e criada - pela jurisprudência do Tribunal Constitucional alemão e que foi recepcionada pela jurisdição brasileira, que, nas suas melhores representações, atua em prol da sua defesa e garantia e, por via de consequência, acabam afetando a concretização de uma parcela dos direitos fundamentais.

Pretende-se, pois, com o presente estudo, introduzir a reflexão acerca de que a ideia de conflito entre as teorias do mínimo existencial e da reserva do possível é aparente e não culmina, necessariamente, em escolhas trágicas, notadamente se considerando o conteúdo do mínimo existencial. A partir daí, lançam-se três questionamentos à jurisdição brasileira, sendo eles: "por que a jurisdição deve conhecer a Análise Econômica do Direito?", "por que a jurisdição deve estar atenta aos discursos (vazios) da reserva do possível?" e 
"por que a jurisdição deve priorizar o mínimo existencial?", todas no intuito de servirem como meio de reflexão ao julgador, notadamente quando da necessidade da prestação jurisdicional em casos que demandem alocação de recursos, visando, ao fim e ao cabo, contribuir para a concretização do mínimo existencial e para que justas decisões sejam lançadas pela jurisdição.

\section{POR QUE A JURISDIÇÃO DEVE CONHECER A ANÁLISE ECONÔMICA DO DIREITO?}

A análise econômica do direito ${ }^{3}$ ganhou grande expressão na década de 1960, na escola de Chicago e, em máxima síntese, consiste na "implementação de um ponto de vista econômico no trato das questões que eram eminentemente jurídicas" (ROSA; LINHARES, 2009, p.55). Calca-se sobre quatro princípios da economia: escassez, escolha racional (maximização), equilíbrio e eficiência. A escassez aclara que todos os recursos são finitos, diferentemente das demandas, que são sempre infinitas, de modo que os agentes devem lidar com escolhas constantemente (SALAMA, 2008, p.54). A escolha racional "consiste em encontrar uma alternativa que maximiza a utilidade do agente económico [sic] dadas as restrições que enfrenta" (SALAMA, 2008, p.55), ou seja, ele deverá optar pela alternativa que traga maior benefício diante da escassez. O equilíbrio trata do ponto em que todos os agentes conseguem maximizar seus interesses diante das escolhas que fazem e das relações que se interligam. Por fim, a eficiência pode ser simploriamente conceituada como a maximização dos ganhos e a minimização dos custos (SALAMA, 2008, p.55).

Empenha-se, ainda, em dois nichos principais: o primeiro em analisar e sugerir a aplicação do direito a partir das bases da economia (análise normativa) e o segundo em responder como as instituições do direito - também o Poder Judiciário e as Leis - podem afetar o comportamento da sociedade de um modo geral (análise positiva) (COOTER; ULEN, 2010, p.25).

\footnotetext{
${ }^{3}$ Refere-se a analise econômica do direito como movimento acadêmico, recordando, por oportuno, que existem diversas formas de abordagem do tema.
} 
Neste sentido, já há algum tempo se tem conhecimento de que as decisões judiciais implicam em consequências - não só jurídicas e econômicas, mas também comportamentais - para a sociedade (RODRIGUES, 2007, p.7), notadamente aquelas que digam respeito a questões íntimas às relações da coletividade (sociedade como um todo). Daí porque se entende como correto que a jurisdição esteja atenta à sua atividade tanto no espaço legal, quanto no âmbito das demais decorrências possíveis, já que:

[...] as cortes influenciam de maneira direita a atividade econômica. Desse modo, seria aparentemente desejável que as cortes tivessem os deveres de compreender as consequências econômicas de suas decisões e, na medida em que isso fosse possível sem que se criasse muita incerteza acerca do próprio comando da ordem jurídica, de levar em conta tais consequências ao exercerem sua competência decisória (COASE, 2010, p.81).

Um bom exemplo disso foi sublinhado pelo Ministro Gilmar Mendes ao apreciar o AgR 47/PE. Na ocasião, em que se debatia o direito à saúde, foi destacado pelo julgador que a efetivação de direitos - naquele caso, os sociais - através do Poder Judiciário deve ser uma tarefa diligente e ponderada, não obstante, no Brasil, cada vez mais remansoso é o entendimento de que os direitos fundamentais são direitos de aplicabilidade imediata e direta. A atuação do Poder Judiciário, salienta o Ministro, não pode perder de vista os argumentos que destacam a escassez de recursos, as escolhas para alocação dos mesmos, critérios de macrojustiça e microjustiça e a otimização da aplicação de recursos por meio de políticas públicas ${ }^{4}{ }^{-}$.

\footnotetext{
${ }^{4}$ Em seu voto fez constar: "A dependência de recursos econômicos para a efetivação dos direitos de caráter social leva parte da doutrina a defender que as normas que consagram tais direitos assumem a feição de normas programáticas, dependentes, portanto, da formulação de políticas públicas para se tornarem exigíveis. Nesse sentido, também se defende que a intervenção do Poder Judiciário, ante a omissão estatal quanto à construção satisfatória dessas políticas, violaria o princípio da separação dos Poderes e o princípio da reserva do financeiramente possível. Dessa forma, em razão da inexistência de suportes financeiros suficientes para a satisfação de todas as necessidades sociais, enfatiza-se que a formulação das políticas sociais e econômicas voltadas ã implementação dos direitos sociais implicaria, invariavelmente, escolhas alocativas. Essas escolhas seguiriam critérios de justiça distributiva (o quanto disponibilizar e a quem atender), configurando-se como típicas opções políticas, as quais pressupõem "escolhas trágicas" pautadas por critérios de macrojustiça. É dizer, a escolha da destinação de recursos para uma política e não para outra leva em consideração fatores como o número de cidadãos atingidos pela política eleita, a efetividade e a eficácia do serviço a ser prestado, a maximização dos resultados etc. Nessa linha de análise, argumentase que o Poder Judiciário, o qual estaria vocacionado a concretizar a justiça do caso concreto
} 
Uma advertência deve ser feita, portanto: a jurisdição deve conhecer a análise econômica do direito, considerá-la, mas não necessariamente deve priorizá-la diante dos objetivos e princípios constitucionais. Ela serve, como útil ferramenta e como boa instância de reflexão para o Poder Judiciário; e ponto. Não pode ser vista como um norte, tampouco como um fim em si mesmo, carecendo sempre estar acompanhada de um fundamento constitucional que a ampare. Caso contrário, riscos inerentes à análise pura e simples da economia - como uma análise puramente utilitarista - podem aparecer ${ }^{6}$. Em outros termos, adianta-se, desde logo, que sempre prevalecerá o comando constitucional mais adequado à questão debatida (ROSA; LINHARES, 2009, p.133-140).

Não se pode ser romântico ao ponto de deixar escapar que, para a análise econômica do direito, o Poder Judiciário brasileiro - e por que não pensar o direito constitucional brasileiro - é tido como um entrave para o pleno desenvolvimento do país. Isto porque o comprometimento da jurisdição com a Constituição e com os princípios e regras ali presentes não parece simpático à economia, pois tende a gerar a estagnação econômica, desequilíbrios no mercado e arrepios ao capital internacional (ROSA; LINHARES, 2009, p.5859). Do mesmo modo, em contrapartida, a lógica fria e utilitarista da economia não parece de todo adequada ao direito. Há, é verdade, uma tensão natural

(microjustiça), muitas vezes não teria condições de, ao examinar determinada pretensão à prestação de um direito social, analisar as conseqüências globais da destinação de recursos públicos em benefício da parte, com invariável prejuízo para o todo".

${ }^{5}$ Valiosa ponderação é realçada pelo Desembargador e doutrinador Rogério Gesta Leal (2009, p. 79): "E por que não se pode resolver tal matéria em termos de tudo ou nada? Pelo fato de que ela envolve outro universo de variáveis múltiplas e complexas, a saber: disponibilidade de recursos financeiros alocados preventivamente, políticas públicas integradas em planos plurianuais e em diretrizes orçamentárias, medidas legislativas ordenadoras de receitas e despesas públicas, etc. Todos estes condicionantes, por sua vez, encontram-se dispersos em diferentes atores institucionais com competências e autonomias reguladas também pela constituição".

6 "A resposta coerente na base da principiologia da Carta de 1988 seria: tratar todos! E se os recursos não são suficientes, deve-se tira-los de outras áreas (transporte, fomento econômico, serviço de dívida) ${ }^{6}$ onde sua aplicação não está tão intimamente ligada aos direitos mais essenciais do homem: sua vida, integridade física e saúde. Um relativismo nessa área pode levar a "ponderações" perigosas e anti-humanistas do tipo "por que gastar dinheiro com doentes incuráveis ou terminais?" etc.". (KRELL, 2002, p.52-53). 
entre direito e econômica, o que não significa dizer, contudo, que não possam cooperar mutuamente ${ }^{7}$ (COASE, 2010, p.81).

Daí porque se vê a análise econômica do direito como agradável procedimento de avaliação das suas decisões, tanto no presente quanto no futuro, já que, através de seus instrumentos, possibilita ao julgador uma visão ampla do problema enfrentado, tanto em nível de microjustiça quanto em nível de macrojustiça. Em outros termos, a análise econômica do direito fornece um método de avaliação dos efeitos da sua decisão - já considerando os quatro princípios da economia ao lado do direito aplicável. Há, pois, um olhar que se pretende diligente no que concerne ao que é dado, ao quanto é dado e a quem é dado ${ }^{8}$ :

\begin{abstract}
Então, concluiu-se até aqui que o modelo de Estado concebido pela Constituição Federal, faz com que se admitam verdadeiros deveres jurídicos prestacionais (de serviço e assistenciais) em favor da coletividade. Se é verdade que se deve procurar uma interpretação que garanta ao máximo o respeito aos direitos fundamentais, por outro lado, isso não significa uma leitura de curto prazo, que não reflete sobre o futuro. A realidade orçamentária não pode ser compreendida como peça de ficção. O desperdício de recursos públicos em um universo de escassez, gera injustiça com aqueles potenciais destinatários a que deles deveriam atender.

[...]

A sua solução, ou, em outras palavras, a ponderação concreta deve estar comprometida não só com a disputa argumentativa (melhor argumento apresentado), mas também com o resultado (a solução em jogo que tende a atender de modo mais abrangente o maio número de pessoas necessitadas de recursos sociais (mais utilidade social e, portanto, de eficiência paretiana). Por exemplo, pode ser
\end{abstract}

\footnotetext{
${ }^{7}$ Em termos macroeconômicos tal tensão havia sido destaca há um bom tempo pelo americano Robert Kennedy, quando criticou que uma análise econômica de crescimento de uma nação por meio do PIB era um erro crasso, pois não refletia o crescimento da qualidade da saúde, da educação, da felicidade, dentre outros valores. Diante de tais termos, a resposta do economista Gregory Mankiw: "Muito do que Robert Kennedy disse está correto. Então, por que nos preocuparmos com o PIB? A resposta é que um PIB elevado nos ajuda, de fato, a levar uma vida confortável. O PIB não mede a saúde das crianças, mas países com PIBs maiores podem arcar com o custo de um melhor atendimento de saúde para suas crianças. O PIB não mede a qualidade da educação, mas países com PIBs maiores podem ter sistemas educacionais melhores. O PIB não mede a beleza da nossa poesia, mas países com PIBs maiores podem ensinar mais cidadãos a ler e a apreciar a poesia. O PIB não leva em conta a nossa inteligência, integridade, coragem, sabedoria ou devoção ao país, mas todos esses louváveis atributos são ais fáceis de desenvolver quando as pessoas estão menos preocupadas em garantir as necessidades materiais da vida" (MANKIW, 2005, p.216).

8 "Além de uma teoria científica do comportamento, a economia fornece um padrão normativo útil para avaliar o direito e as políticas públicas. As leis não são apenas argumentos arcanos, técnicos; elas são instrumentos para atingir objetivos sociais importantes. Para conhecer os efeitos das leis sobre esses objetivos, os juízes e outros legisladores precisam ter um método para avaliar os efeitos das leis sobre valores sociais importantes" (COOTER E ULEN, 2010, p. 26).
} 
mais eficiente diminuir a mortalidade infantil na África empregando os escassos recursos existentes em combater a desidratação do que a AIDS, se maior número de crianças morrerem da primeira causa e ela for mais barata de combater (TIMM, 2010 p.60).

O que parece restar evidenciado neste ponto à jurisdição é que, ao se falar de proteção aos direitos fundamentais e em controle judicial de políticas públicas, a decisão judicial não pode ser apenas jurídica, ela tem que ser também econômica - não determinante, mas como face a ser considerada -. Jurídica ao proteger, garantir e concretizar direitos, porém econômica ao ponderar critérios de escolha racional e eficiência, evitando-se desperdícios diante do cenário de escassez. Tudo isso, entretanto, deve estar acompanhado de um discurso fundamentado e exaustivo acerca das razões jurídicas (melhor argumento) e econômicas (melhor utilidade), lançadas como parâmetros pelo julgador.

\section{POR QUE A JURISDIÇÃO DEVE ESTAR ATENTA AOS DISCURSOS (VAZIOS) DA RESERVA DO POSSIVEL?}

Por todas as características que revestem os direitos fundamentais, cabe ao Estado à função elementar de realizar tais direitos, máxime quando se tratar dos direitos fundamentais sociais, lidando ${ }^{9}$ com significantes variáveis e demandas judiciais em seu desfavor, que buscam a realização dos direitos fundamentais ${ }^{10}$. Neste universo de ações judiciais movidas contra o Estado, um

\footnotetext{
9 "[...] en cambio, tras los derechos sociales existen además normas secundarias o de organización que, por así decirlo, se interponen entre el derecho y la obligación, entre el sujeto acreedor y el sujeto deudor. Tal vez éste sea uno de los motivos que explican las particulares dificultades de los derechos prestacionales: las libertades generan un tipo de relación jurídica sencilla donde los indivíduos saben perfectamente en qué consisten sus derechos y deberes recíprocos, mientras que estos otros derechos requieren un previo entramado de normas de organización, por cierto carentes de exigibilidad, que a su vez generan una multiplicidad de obligaciones jurídicas de distintos sujetos, cuyo cumplimiento conjunto es necesario para la plena satisfacción del derecho" (SANCHÍS, 2009, p.177).

${ }_{10}$ Interessante ponderação é realizada por Andreas Krell (2002, p.19-20), ao dizer que: "Os Direitos Fundamentais Sociais não são direitos contra o Estado, mas sim direitos através do Estado, exigindo do poder público certas prestações materiais. São os Direitos Fundamentais do homem-social dentro de um modelo de Estado que tende cada vez mais a ser social, dando prevalência aos interesses coletivos antes que aos individuais. O Estado, mediante leis parlamentares, atos administrativos e a criação real de instalações de serviços públicos, deve definir, executar e implementar, conforme às circunstâncias, as chamadas 'políticas sociais' (de educação, saúde, assistência, previdência, trabalho, habitação) que facultem o gozo efetivo dos direitos constitucionalmente protegidos".
} 
espaço igualmente farto de debates jurídico-políticos é visto, nos quais se vêem desde discussões quase superadas como a eficácia jurídica das normas de direitos fundamentais até outras mais inflamadas, como a quebra do princípio democrático e da separação dos Poderes pelo Judiciário, quando da concretização de determinado direito fundamental que demande dispêndio de valores ${ }^{11}$.

Canotilho (2004, p.100-101) anotou em seus estudos que, em face da inflação desmedida de novos direitos sociais e de demandas por tais direitos cada vez mais complexas e/ou volumosas - somando-se à máxima de que as demandas são infinitas, mas os recursos são finitos -, a plena concretização dos direitos fundamentais que demandem empenho de recursos somente se dará de forma gradativa (CANOTILHO, 2010, p.12-13), nos limites do possível. Cunhou-se, daí, a chamada teoria da reserva do possível à brasileira (ou teoria da reserva do financeiramente possível ${ }^{12}$ ), que engordou o fuzzysmo ${ }^{13}$ que envolve a matéria:

\footnotetext{
${ }^{11}$ Anota-se, por oportuno, a posição de Luís Roberto Barroso (2010, p.390-391): "O debate, na sua essência, é universal e gravita em torno das tensões e superposições entre constitucionalismo e democracia. É bem de ver, no entanto, que a ideia de democracia não se resume ao princípio majoritário, ao governo da maioria. Há outros princípios a serem preservados e há direitos da minoria a serem respeitados. Cidadão é diferente de eleitor; governo do povo não é governo do eleitorado. No geral, o processo político majoritário se move por interesses, ao passo que a lógica democrática se inspira em valores. E, muitas vezes, só restará o Judiciário para preservá-los".

12 "[...] se considerou como limite absoluto à efetivação de direitos fundamentais sociais (i) a suficiência de recursos públicos e (ii) a previsão orçamentária da respectiva Despesa" (MANICA, 2007, p.169-186).

13 "A nosso ver, paira sobre a dogmática e teoria jurídica dos direitos econômicos, sociais e culturais a carga metodológica da «vaguidez», «indeterminação» e «impressionismo» que a teoria da ciência vem apelidando, em termos caricaturais, sob a designação de «fuzzysmo" ou «metodologia fuzzy». [...] Em toda a sua radicalidade, a censura de «fuzzysmo» lançada aos juristas significa basicamente de que eles não sabem do que estão a falar quando abordam os complexos problemas dos direitos econômicos, sociais e culturais. Assim, por exemplo, [...] Ao abordarmos o "direito à universidade» teremos, nós, constitucionalistas alguma idéia [sic] sobre a estrutura da procura de trabalho e da bolsa de emprego? Ao insistirmos nos novos direitos sociais de minorias populacionais, como por exemplo, dos indivíduos soropositivos (isto é, doentes com SIDA), saberemos que cada indivíduo gasta nos dois últimos anos terminais da doença alguma coisa como doze milhões de escudos por ano, o equivalente a um apartamento de duas assoalhadas? [...] os direitos sociais aparecem envoltos em quadros pictóricos onde 0 recorte jurídico cede o lugar a nubelosas normativas. É aqui que surge o camaleão «normativo». [...] Com ela pretendia ela significar a instabilidade e imprecisão normativa de um sistema jurídico aberto - como o dos direitos sociais - [...] Esta indeterminação normativa explicaria, em grande medida, a confusão entre conteúdo de um direito juridicamente definido e determinado e sugestão de conteúdo sujeita a modelações político-jurídicas cambiantes. Por outras palavras: o «transformismo normativo» dará azo à passagem de um discurso jurídico rigoroso centrado em categorias como «direitos subjectivos» e «deveres jurídicos» para um
} 


\begin{abstract}
Essa teoria, na verdade, representa uma adaptação de um topos da jurisprudência constitucional alemã (Der Vorbehalt des Möglichen), que entende que a construção de direitos subjetivos à prestação material de serviços públicos pelo Estado está sujeita à condição da disponibilidade dos respectivos recursos. Ao mesmo tempo, a decisão sobre a disponibilidade dos mesmos estaria localizada no campo discricionário das decisões governamentais e dos parlamentos, através da composição dos orçamentos públicos (KRELL, 2002, p.52).
\end{abstract}

Não se olvida, entretanto, que conceitos transplantados de outros sistemas jurídicos - no caso da reserva do possível, do sistema alemão para o brasileiro $^{14}$ - devem sofrer a justa adequação quando incorporados ao direito pátrio, observando-se o contexto próprio do ordenamento que os acolhe (BREUS, 2007, p.234). Esta adaptação não pode, porém, ser míope e desvirtuar características e limites próprios da teoria. Diz-se isso porque, originalmente, a Teoria da reserva do possível apareceu no julgamento do BverfGE n. ${ }^{\circ} 33$, S. 303, do Tribunal Constitucional alemão ${ }^{15}$, que entendeu que "o direito à prestação positiva - no caso, o aumento do número de vagas na universidade - encontra-se sujeito à reserva do possível, no sentido daquilo que o indivíduo pode esperar, de maneira razoável da sociedade" (MÂNICA, 2007, p.177). Vê-se, pois, que a teoria da reserva do possível não tratou, originariamente, da (in)existência de recursos materiais para a efetivação dos direitos fundamentais propriamente dita, mas sim da razoabilidade da postulação apresentada ${ }^{16}$.

discurso político-constitucional baseado em programas concretizadores de «princípios sectores» e de directivas políticas" (CANOTILHO, 2004, p.100-101).

${ }_{14}$ "Na base do acima exposto, fica claro que uma transferência mal refletida do conceito da "reserva do possível" e do entendimento dos direitos sociais como mandados (e não legítimos Direitos Fundamentais) constituiria uma "adoção de soluções estrangeiras, nem sempre coerentes com as verdadeiras necessidades materiais" do país, que, "há muitas décadas, pode ser observada na elaboração jurídica brasileira" (KRELL, 2002, p.56).

15 "No caso, a Corte alemã analisou demanda judicial proposta por estudantes que não haviam sido admitidos em escolas de medicina de Hamburgo e Munique em face da política de limitação do número de vagas em cursos superiores adotada pela Alemanha em 1960. A pretensão foi fundamentada no artigo 12 da Lei Fundamental daquele Estado, segundo a qual "todos os alemães têm direito a escolher livremente sua profissão, local de trabalho e seu centro de formação" (MÂNICA, 2007, p.169).

${ }^{16}$ Parece claro que a razoabilidade tem relação com os recursos disponíveis. Algo que pode parecer razoável num determinado contexto de fartura pode deixar de sê-lo em um contexto de escassez. Mas este argumento, como se verá adiante, não pode ser, por si só e exclusivamente, o fator determinante ou o elemento central da decisão judicial. 
Trabalhar, no plano político-jurídico, com a ideia de que o condicionamento dos direitos fundamentais deve ser dependente dos valores existentes nos caixas do Poder Executivo parece disparate, já que, ao fim e ao cabo, estar-se-ia substituindo a vencida teoria da programaticidade de determinadas normas de direitos fundamentais pela teoria da reserva do possível, reforçando-a com argumentos como separação de poderes e discricionariedade administrativa. Estar-se-ia, assim, próximo de se cogitar acerca da reversibilidade social ou do esvaziamento do conteúdo mínimo dos direitos fundamentais.

Neste sentido, agrega-se que, no Brasil, criou-se, em torno da teoria da reserva do possível, um discurso que se tornou banalizado em seu uso, representando, não raras vezes, uma alegação vazia de defesa processual ${ }^{17}$, invocada por um Estado que busca, por meio de discursos ligados a escolhas e a limites econômicos e financeiros, fugir de suas obrigações constitucionais ${ }^{18}$. Neste sentido bem salienta Breus (2007, p.232-233):

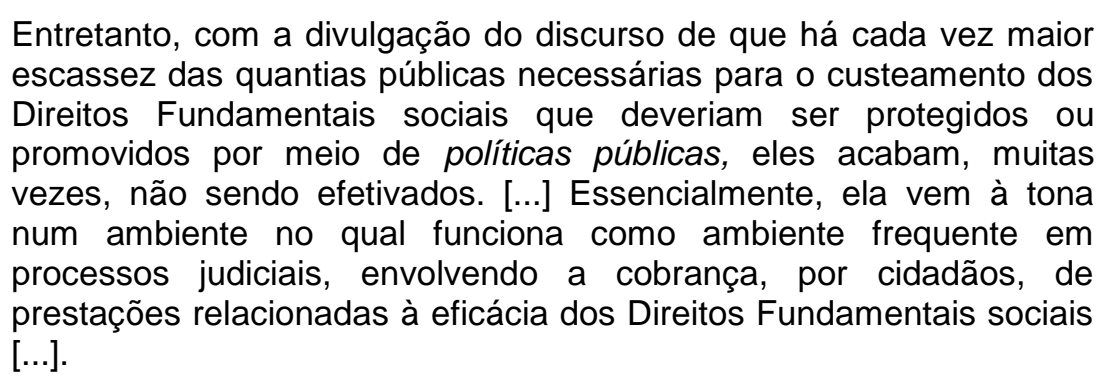

A importância de se ter à frente uma jurisdição comprometida com a dignidade humana, atuando como escudo último de direitos fundamentais, passa a ganhar, assim, especial destaque nesse cenário, pois, sabendo diferenciar alegações de fatos, pode ela aplicar adequadamente a - sempre invocada - teoria da reserva do possível. Atento a isso, o Supremo Tribunal Federal já advertiu que a reserva do possível constitui a exceção no sistema

\footnotetext{
17 “[...] na ausência de um estudo mais aprofundado, a reserva do possível funcionou muitas vezes como o mote mágico, porque assustador e desconhecido, que impedia qualquer avanço na sindicabilidade dos direitos sociais" (BARCELLOS, 2002, p.237).

${ }_{18}$ Canotilho (2004, p.107-108) anota quanto aos direitos sociais, que pode ocorrer a desvinculação jurídica do legislador, que tende a ficar próximo do zero em eficácia jurídica e engessa a atuação do poder judiciário diante de opções legislativas nem sempre acertadas.
} 
jurídico brasileiro, somente podendo ser alegada quando acompanhada de prova objetivamente aferível acerca da escassez declarada ${ }^{19}$.

De outro lado, retomando-se o que foi dito em momento anterior, a jurisdição deve saber diferenciar, a partir dos postulados da análise econômica do direito, os efeitos de uma decisão que afete um espaço de microeconomia e um espaço de macroeconomia. No primeiro caso, fala-se de processos judiciais, tomados um a um. Já no segundo caso está-se diante de políticas públicas judicializadas, numa perspectiva mais coletiva que individual. E não só porque irá afetar os cofres públicos - como insiste a teoria da reserva do financeiramente possível -, mas verdadeiramente porque se deverá realizar um exercício de proporcionalidade da pretensão, uma proporcionalidade que deverá ser tanto jurídica (princípio da proporcionalidade), quanto econômica (analise econômica do direito), como se verá a seguir.

\section{POR QUE A JURISDIÇÃO DEVE PRIORIZAR O MÍNIMO EXISTENCIAL?}

"Por que a jurisdição deve priorizar o mínimo existencial?" Simplesmente porque toca parte elementar dos direitos fundamentais, que representam 0 respeito à dignidade da pessoa humana e o meio pelo qual ela será concretizada (SARLET, 2010, p.70). Não bastasse isso, também porque os direitos fundamentais, dada a sua importância singular para a integridade humana, representam a máxima instância de direitos a serem tutelados e protegidos, sendo instituídos, por tal razão, em nível constitucional, com méritos de superconstitucionalidade (BRANDÃO, 2010, p.451), no sentido de serem tidos como os principais direitos de um ordenamento jurídico.

O reconhecimento histórico - e jurídico - dos direitos fundamentais se presta para aclarar a razão de por que eles podem ser vistos, tal como no dizer

\footnotetext{
${ }^{19}$ Assim foi o voto do Ministro Celso de Mello na ADPF n. 45: "[...] a cláusula da "reserva do possível" - ressalvada a ocorrência de justo motivo objetivamente aferível - não pode ser invocada, pelo Estado, com a finalidade de exonerar-se, dolosamente, do cumprimento de suas obrigações constitucionais, notadamente quando, dessa conduta governamental negativa, puder resultar nulificação ou, até mesmo, aniquilaçáo de direitos constitucionais impregnados de um sentido de essencial fundamenta1idade".
} 
de Paulo Gilberto Cogo Leivas ${ }^{20}$, como direitos que não podem ser entregues à boa vontade da maioria, configurando direitos subjetivos a serem pleiteados, mormente, em face do Estado ${ }^{21}$.

A respeito disso, o Tribunal Constitucional Federal alemão, ao apreciar o BverfGE 82, $60^{22}$, que debatia a inconstitucionalidade da Lei do Abono Família aos filhos, fez menção expressa ao direito ao mínimo existencial (Existenzminimum) (LEIVAS, 2006, p.130), asseverando que este corresponde à garantia e à prestação daquilo que se mostrasse necessário para uma vida com dignidade (TORRES, 2010, p.37), não apenas como um fim em si mesmo, mas como forma de promoção e de proteção à dignidade humana (SARLET; FIGUEIREDO, 2010, p.21). O mínimo existencial corresponderia, pois, à última parte existente do direito fundamental, que nem sempre se confunde com o seu núcleo essencial ${ }^{23}$. Abaixo deste nível não há mais deferência ao direito fundamental, notadamente porque não haverá prestação ou gozo do direito com dignidade (humana). Em conspícua lição, Corinna Treisch ${ }^{24}$ apresenta conceito bastante completo e adequado do que venha a ser o mínimo existencia ${ }^{25}$ ao aduzir que:

20 "[...] em sentido material, direitos a ações positivas fáticas, que, se o indivíduo tivesse condições financeiras e encontrasse no mercado oferta suficiente, poderia obtê-las de particulares, porém, na ausência dessas condições e, considerando a importância destas prestações, cuja outorga ou não-outorga não pode permanecer nas mãos da simples maioria parlamentar, podem ser dirigidas contra o Estado por força de disposição constitucional" (LEIVAS, 2006, p.89).

21 "[...] os direitos sociais demandam medidas redutoras de desigualdades - não por acaso o velho Marx dizia que igualdade é igualação - e essas medidas dependem quase que exclusivamente de investimentos estatais, até porque a solidariedade não é algo que se possa impor a mentes e corações egoístas [...]" (MENDES; COELHO; BRANCO, 2008, p.713),

${ }^{22}$ ALEMANHA. Bundesverfassungsgericht. BVerfGE 82, 60, 29 Mai 1990. Disponível em: Disponível em: http://www.servat.unibe.ch/dfr/bv082060.html. Acesso em: 20/10/2011.

${ }_{23}$ "Que este núcleo essencial, em muitos casos, até pode ser identificado com o conteúdo em dignidade destes direitos e que, especialmente em se tratando de direitos sociais de cunho prestacional (positivo) este conteúdo essencial possa ser compreendido como constituindo justamente a garantia do mínimo existencial, resulta evidente. Por outro lado, tal constatação não afasta a circunstância de que, quando for o caso, este próprio conteúdo essencial (núcleo essencial = mínimo existencial) não é o mesmo em cada direito social (educação, moradia, assistência social, etc.) [...]" (SARLET; FIGUEIREDO, 2010, p.26). Ao contrário: "Os direitos sociais se transformam em mínimo existencial quando são tocados pelos interesses fundamentais ou pela jusfundamentabilidade. A ideia de mínimo existencial, por conseguinte, coincide com a de direitos fundamentais sociais em seu núcleo essencial (TORRES, 2010, p.42).

${ }_{24}^{24}$ Corinna Treisch apud LEIVAS (2006, p.135).

${ }^{25} \mathrm{Em}$ complemento: "Ainda no contexto do debate jurídico-constitucional alemão, verifica-se uma distinção importante no concernente ao conteúdo e alcance do próprio mínimo existencial, que tem sido desdobrado num assim designado mínimo fisiológico, que constituí, por 
O mínimo existencial é a parte de consumo corrente de cada ser humano, seja criança ou adulto, que é necessário para a conservação de uma vida humana digna, o que compreende a necessidade de vida física, como a alimentação, vestuário, moradia, assistência de saúde, etc. (mínimo existencial físico) e a necessidade espiritualcultural, como educação, sociabilidade, etc. Compreende a definição do mínimo existencial tanto a necessidade física como também cultural-espiritual, então se fala de um mínimo existencial cultural.

No que tange especificamente aos direitos fundamentais sociais, a proteção da dignidade da pessoa humana pelo mínimo existencial é íntima da ideia de satisfação dessas necessidades humanas com vistas à qualidade de vida, que invoca bem-estar, acesso e fruição de bens materiais e imateriais essenciais para a dignidade humana - e não apenas vitais ${ }^{26}$. Há que se distinguir, portanto, pelo menos três níveis de satisfação dessas necessidades: um nível vital, onde haverá vida, sobrevivência, mas com nenhuma dignidade; um nível essencial (existencial ou básico) ${ }^{27}$, onde o indivíduo pode conduzir sua vida com certa dignidade, ainda que não plena, suportando algumas limitações; e um nível ideal, no qual há integral satisfação das necessidades e inteira dignidade humana, pelo menos em um nível de generalização abstrata:

compreender as condições materiais mínimas para uma vida condigna, no sentido da proteção contra necessidades de caráter existencial básico, o conteúdo essencial da garantia do mínimo existencial, e um assim designado mínimo existencial sociocultural, que, para além da proteção básica já referida, objetiva assegurar ao indivíduo um mínimo de inserção - em termos de tendencial igualdade na vida social -“ (SARLET; FIGUEIREDO, 2010, p.24).

26 "Em primeiro lugar, deve-se ter presente que qualidade de vida, contemporaneamente, não implica o simples afastar os perigos provocados pelo próprio homem/inimigo, pela natureza ou pelos deuses. [...] A transformação da sociedade, em especial pela transformação das relações de produção impostas pelo desenvolvimento tecnológico, com a introdução da máquina e de uma nova lógica de organização do tempo, impôs o alargamento deste conceito, incorporando, posteriormente, os "benefícios" da vida urbana. Ou seja, ter qualidade de vida passou a significar a possibilidade de desfrutar dos mecanismos criados pelo próprio homem e que substituíam-no na prática de tarefas árduas e penosas. [...] a ideia de qualidade de vida passa a incorporar a possibilidade de consumo constante das novidades tecnológicas postas à disposição no mercado mundial [...]" (MORAIS, 1996, p.182).

${ }_{27}$ Trabalha-se com a nomenclatura "nível essencial ou existencial ou básico" e não outras conhecidas, tais como "ótimo-mínimo" ou apenas "ótimo", por entender que todos os seres humanos deveriam contar inicialmente com esse nível de dignidade e de atendimento das suas necessidades para ter sua condição de ser humano respeitada e, a partir daí, galgar melhores condições. Ademais, leva-se em consideração que a dignidade da pessoa humana, máxime em países em desenvolvimento, é um objetivo em constante busca pela sua concretização plena, que demanda o atendimento de um universo de significantes, muitas das quais hoje utópicas, de sorte que a definição de "nível essencial ou existencial ou básico" é amarrada a ideia de "máximo possível", sempre tendo a frente (e contando com) a atuação ética, comprometida, solidária e moral do Estado e dos indivíduos. 
A próxima tarefa consiste em investigar padrões de satisfação de necessidades básicas. O primeiro padrão possível corresponde ao nível mais ínfimo de satisfação das necessidades, como, por exemplo, dispor de quantidade mínima de água, oxigênio e aporte calorífico suficiente para conservar a vida. [...]

Há dois níveis ótimos de satisfação de necessidades: ótimo mínimo e ótimo máximo. No nível ótimo mínimo a saúde física e a autonomia são tais que o individuo é capaz de optar por atividades nas quais deseje tomar parte dentro de sua própria cultura, possui aptidões cognitivas, anímicas e sociais para fazê-lo e tem acesso aos meios que o permitam adquirir ditas aptidões. No segundo nível, chamado também de ótimo crítico, a saúde e autonomia são tais que o individuo pode formular os objetivos e ideias necessárias para questionar sua forma de vida, participar de um processo político encaminhado para tal fim e, se o deseja, adotar outro tipo de cultura.[...]

Um nível ótimo mínimo talvez seja o objetivo urgente a ser alcançado. Ótimo-mínimo ou "minopt" não corresponde, porém, a um nível ínfimo de sobrevivência (LEIVAS, 2006, p.126).

Neste sentido, uma definição dos limites de ditos níveis de satisfação, ainda que generalizante, observadas as condições cambiantes de um Estado para outro, parece ser elementar tanto para fins de formulação e de execução de políticas públicas quanto para fins de atuação jurisdicional, já que, salvo melhor juízo, somente as instâncias de satisfação vital e essencial (existencial) poderão ser objeto de sindicalização judicial individual com alguma razão preliminar - ou seja, sem uma análise inicial mais detida do mérito e das condições financeiras existentes - diante da coletividade $^{28}$ e de responsabilidade estatal, máxime porque a terceira instância somente poderá ser alcançada pela ação sinérgica do Estado com o individuo.

Vê-se, pois, a importância de se reconhecer que a teoria jurídica do mínimo vital não se confunde com a do mínimo existencial ${ }^{29}$. Este último, com

\footnotetext{
28 "O necessário, segundo Doyal e Gough, é um padrão ótimo crítico ou máximo de saúde e autonomia. Na prática, isso significa alcançar o melhor nível de satisfação de necessidade que se alcance em qualquer lugar do mundo na época atual ou um padrão ainda maior que seja possível em nosso tempo. Reconhece, todavia, que, para países do terceiro mundo, um nível ótimo como este não é realista, embora ele continue a ser o único crítico lógico e moral que é possível aplicar à valoração da satisfação a longo prazo das necessidades. Para tais países, pode-se extrair níveis mais baixos como objetivos de uma estratégia a médio prazo" (LEIVAS, 2006, p.126-127).

29 "[...] conteúdo do designado mínimo existencial, que não pode ser confundido com o que se chamado de mínimo vital ou um mínimo de sobrevivência, de vez que este último diz com a garantia da vida humana, sem necessariamente abranger as condições para uma sobrevivência física em condições dignas, portanto, de uma vida com certa qualidade" [...] uma eventual limitação do núcleo essencial do direito ao mínimo existencial a um mínimo fisiológico, no sentido de uma garantia apenas das condições materiais mínimas que impedem seja colocada em risco a própria sobrevivência do indivíduo, poderá servir de pretexto para a
} 
base na divisão acima indicada, enquadra-se no nível da essencialidade ${ }^{30}$ ( BITTENCOURT NETO, 2008, p.118), enquanto que o primeiro se localiza na primeira faixa, a do ínfimo. Juridicamente, ainda que se tenha como "certo que a garantia efetiva de uma existência digna abrange mais do que a garantia da mera sobrevivência física" (FIGUEIREDO, 2010, p.21), a confusão conceitual permanece em algumas esferas doutrinárias e jurisprudenciais.

Por mais que pesquisas revelem que existem diversos países onde nem mesmo o mínimo vital é adequadamente prestado, tem-se que, para além dessas distinções conceituais, o fato é que, em se garantindo o mínimo existencial, estar-se-á garantindo, por via de consequência, também o mínimo vital.

Daí já se depreende por que a jurisdição brasileira deve, sempre, dar importância destacada ao mínimo existencial, notadamente porque tem o Poder Judiciário (e o Estado como um todo) "não apenas uma proibição de excesso (Übermassverbot), mas também uma proibição de proteção insuficiente (Untermassverbot)" (BRASIL, STF, 2010), significando dizer que se valer ou se perder em argumentos vazios de conteúdo, para a não concretização dos direitos fundamentais, importaria em afronta direta à Constituição, em sua unidade, bem como a sua força normativa.

Tal posicionamento foi e vem sendo ratificado pelo Supremo Tribunal Federal em outros julgados, evidenciando que, pelo menos no que toca ao denominado "mínimo existencial", há um claro e legítimo dever do Poder Judiciário em agir - agir positivo - visando à concretização dos direitos fundamentais sociais, unindo forças com o empenho estatal. Críticas à parte, fica esclarecido que, no que toca ao mínimo existencial, o Poder Judiciário, hoje, conta com inegável poder de transformação das realidades sociopolíticas e é justamente por isso que a sua atuação deve se pautar pela principiologia

redução do mínimo existencial precisamente a um mínimo meramente 'vital' (de mera sobrevivência física)" (SARLET; FIGUEIREDO, 2010, p.23-24).

30 , "[...] a defesa de condições mínimas que possibilitam não apenas a sobrevivência, mas sim a vida com dignidade, vida que requer também elementos sociais, políticos e psicológicos. Ainda, o mínimo existencial é compreendido como o conteúdo determinável do princípio da dignidade da pessoa humana, o núcleo que vincula as ações e omissões do poder público. Trata-se, portanto, de decisão que efetivamente considera o mínimo existencial, tomando-o seriamente" (HONÓRIO, 2009, p.101). 
decorrente da Constituição, que Ihe autoriza a agir em defesa e na garantia desse mínimo, ainda que, para isso, tenha que operar na esfera de atuação primeira de outros Poderes, unindo, para tanto, de um lado, provas objetivas e, de outro, fundamentação e apreciação exaustiva dos aspectos suscitados.

\section{HÁ MESMO ESCOLHAS TRÁGICAS NESTE ÂMBITO?}

A escassez, quando envolve questões peremptórias à vida e à dignidade do homem, culmina, por sua vez, em escolhas tidas como "trágicas" (AMARAL, 2010, p.73-82). No caso do Estado, o mesmo ocorre. Não há como se negar a sensível posição do Estado ao ter que optar entre a construção de uma escola ou de um hospital, em um bairro que necessite de ambos (ou ainda escolher entre dois bairros igualmente necessitados), diante da escassez de recursos. A questão cerne, diante de todo o exposto até o momento, é, portanto: como pode ser trágica uma situação de escolha onde não se tem opção, onde não há escolha? É o que ocorre entre o mínimo existencial e a reserva do possível.

Diante do fato de que as necessidades são infinitas e os recursos são finitos, parece ser razoável que certas demandas sejam atendidas antes do que outras, não sendo, no entanto, essas escolhas, trágicas. Trágico seria se nenhuma das demandas em conflito pudesse ser atendida ou se não se pudesse atendê-las, ao menos parcialmente, de forma concomitante. Um exercício de ponderação racional, que leve em conta a proporcionalidade jurídica e econômica, pode oferecer respostas claras sobre qual demanda deve ser atendida primeiramente, e isso não importa em tragédia alguma, máxime diante da concretização gradativa (mas constante) dos direitos fundamentais ${ }^{31}$.

No caso do mínimo existencial - diferentemente do mínimo vital - isso também ocorre, já que nem sempre se poderá exigir da sociedade algo não razoável ou financeiramente inviável. Por certo que tal situação de impossibilidade de entrega da demanda postulada deve observar critérios objetivos e comprovados de impossibilidade, afastando os discursos vazios. De

\footnotetext{
${ }^{31}$ Lembra-se aqui a ideia de Ronald Dworkin (2002, p.43), no sentido da "Resposta Correta" diante do conteúdo material dos princípios e das normas de caráter aberto.
} 
qualquer sorte, deve-se obervar que há tragédia no não atendimento do mínimo existencial, mas não na sua concretização parcial (mas constante).

Em outros termos, não há uma escolha trágica no embate entre a teoria da reserva do (financeiramente) possível e a teoria do mínimo existencial, já que sequer conflito há, notadamente porque o mínimo existencial, por força constitucional, seja em demanda individual, seja através da judicialização de matéria afeta a uma política pública, sempre deverá ter seu chamado atendido por parte do Estado, pois - reitera-se propositadamente - o mínimo existencial, no âmbito dos direitos fundamentais, acaba configurando a parte última da prestação do direito com dignidade humana.

\section{CONSIDERAÇÕES FINAIS}

Constata-se que não raras vezes o Poder Judiciário tem que agir positivamente para resguardar o mínimo existencial, máxime se estiver diante de um debate que sindicalize o pleito de direito(s) fundamental(is) social(is) ou de uma política pública, já que deverá perseguir a missão constitucional de alcançar justiça distributiva, dignidade humana, proteção a direitos (fundamentais em especial) e bem-estar, ao tempo em que lida com questões políticas e outras tantas mais simpáticas à economia e às finanças.

Há, portanto, que haver a justa e razoável ponderação entre direitos fundamentais, políticas públicas e reserva do possível, uma avaliação que somente pode se dar com base em elementos concretos a serem apresentados ao Judiciário - demonstrados pelo Estado ao longo do processo judicial - e não, simplesmente, pelo discurso vazio e aleatório de insuficiência de recursos e custo dos direitos. Neste espaço também é necessário (e salutar) que o julgador tenha conhecimento dos efeitos diretos de sua decisão, considerando que $o$ agir em microjustiça pode afetar tantas outras situações (macrojustiça).

Os três questionamentos trazidos nesta abordagem se prestam para auxiliar o julgador a encontrar a resposta mais adequada ao caso concreto que aprecia, tendo a sua frente, a partir de deles, que deverá dar prevalência ao mínimo existencial acima das questões veiculadas por argumentos utilitaristas ou vazios; que deverá estar atento as alegações acerca da insuficiência de 
recursos (econômicos ou humanos); e que deverá, apesar de tudo, considerar os efeitos sistêmicos de sua decisão, ainda que tal fator não possa determinar o resultado final da decisão.

É a partir desses fundamentos que a jurisdição não irá se entregar aos discursos vazios advindos das áreas das finanças e da economia para a não concretização dos direitos fundamentais e de políticas públicas, mas que, de outra banda, não irá agir desmedidamente, atingindo inenarrável número de pessoas. Isso se dá, exemplificativamente ao extinguir recursos destinados a outros direitos tão ligados ao mínimo existencial quanto ao apreciado, ou quando desregular e/ou afetar situações advindas do mercado e da economia.

\section{REFERÊNCIAS}

AMARAL, Gustavo. Direito, escassez \& escolha: critérios jurísicos para lidar com a escassez de recursos e as decisões trágicas. 2ed. Rio de Janeiro: Lumen Juris, 2010.

BARCELLOS, Ana Paula. A eficácia jurídica dos princípios constitucionais. O princípio da dignidade da pessoa humana. Rio de Janeiro e São Paulo: Renovar, 2002.

BARROSO, Luís Roberto. Direito constitucional contemporâneo: os conceitos fundamentais e a construção do novo modelo. 2ed. São Paulo: Saraiva, 2010.

BITTENCOURT NETO, Eurico. O direito ao mínimo para uma existência digna. Porto Alegre: livraria do Advogado, 2010.

BRANDÃO, Rodrigo. São os direitos sociais cláusulas pétreas? Em que medida? In: Direitos Sociais: fundamentos, judicialização e direitos sociais em espécie. SOUZA NETO. Cláudio Pereira; SARMENTO, Daniel (orgs.). Rio de Janeiro: Lumen Juris, 2010.

BRASIL, Supremo Tribunal Federal. ADPF no 45, Rel. Ministro Celso Mello, julgada em 29/04/04, DJ, 04/05/2004. Disponível em http://www.stf.jus.br, acesso em 10 mai. 2011.

Supremo Tribunal Federal. AgR-47/PE, Rel. Ministro Gilmar Mendes, julgado em 17/03/2010. Disponível em http://www.stf.jus.br, acesso em 10 fev. 2012. 
BREUS, Thiago Lima. Políticas públicas no Estado Constitucional: problemática na concretização dos direitos sociais pela Administração Pública brasileira contemporânea. Belo Horizonte: Fórum, 2007.

CANOTILHO, José Joaquim Gomes. Estudos sobre direitos fundamentais. Coimbra: Coimbra, 2004.

José Joaquim Gomes. O direito constitucional como ciência de direcção - O núcleo essencial de prestações sociais ou a localização incerta da socialidade (contributo para a reabilitação da força normativa da "constituição social”. In: Direitos fundamentais Sociais. Coord. CANOTILHO, J.J. Gomes; CORREIA, Marcus Orione Gonçalves; e CORREIA, Érica Paula Barcha (Orgs.). São Paulo: Saraiva, 2010.

COASE, Ronald H. O problema do custo social. In:SALAMA, Bruno Mayerhof (Org.) Direito e economia: textos escolhidos. São Paulo: Saraiva, 2010.

COOTER, Robert; ULEN, Thomas. Direito \& economia. 5ed. Porto Alegre: Bookman, 2010.

DWORKIN, Ronald. Levando os Direitos a Sério. Trad. Nelson Boeira. São Paulo: Martins Fontes, 2002.

HONÓRIO, Cláudia. Olhares sobre o mínimo existencial em julgados brasileiros. Dissertação de mestrado apresentada à Universidade Federal do Paraná, $2009 . \quad$ Disponível em: http://dspace.c3sl.ufpr.br:8080/dspace/bitstream/handle/1884/17942/claudia1.p df?sequence=. Acesso em: 16 de junho de 2011.

KRELL, Andreas J. Direitos sociais e controle judicial no Brasil e na Alemanha: os (des) caminhos de um direito constitucional "comparado. Porto Alegre: Sergio Antonio Fabris, 2002.

LEAL, Rogério Gesta. Estado, administração pública e sociedade: novos paradigmas. Porto Alegre: Livraria do Advogado. 2006.

Rogério Gesta. Condições e possibilidades eficaciais dos direitos fundamentais sociais: os desafios do poder judiciário no Brasil. Porto Alegre: Livraria do Advogado. 2009.

LEIVAS, Paulo Gilberto Cogo. Teoria dos direitos fundamentais sociais. Porto Alegre: Livraria do Advogado, 2006.

MÂNICA, Fernando Borges. Teoria da reserva do possível: direitos fundamentais a prestações e a intervenção do poder judiciário na implementação de políticas públicas. In: Revista Brasileira de Direito Público, Belo Horizonte, ano 5, n. 18, p. 169-186, jul./set. 2007. 
MANKIW, Gregory. Princípios de macroeconomia. São Paulo: Pioneira Thomson Learning, 2005.

MENDES, Gilmar Ferreira; COELHO, Inocêncio Martires; BRANCO, Paulo Gustavo Gonet. Curso de direito constitucional. 3 ed. São Paulo: Saraiva, 2008.

ROCHA, SONIA. Pobreza no Brasil: afinal, de que se trata. 2ed. Rio de Janeiro: FGV, 2005.

RODRIGUES, Vasco. Análise económica do direito: uma introdução. Coimbra: Almedina, 2007.

ROSA, Alexandre Morais; LINHARES, José Manuel Aroso. Diálogos com a Law \& Economics. Rio de Janeiro: Lumen Juris, 2009.

SALAMA, Bruno Meyerhof. O que é "direito e economia"?. In: TIMM, Luciano Benetti (Org.). Direito \& economia. 2ed. Porto Alegre: Livraria do Advogado, 2008.

SANCHÍS, Luis Prieto. Los derechos sociales y el principio de igualdad sustancial. In: Direitos fundamentais sociais: Estudos em homenagem aos 60 anos da Declaração Universal dos Direitos Humanos e aos 20 anos da Constituição Federal. Helder Baruffi (Org.). Dourados: UFGD, 2009, p.167-216.

SARLET, Ingo W; FIGUEIREDO, Mariana Filchtiner. Reserva do possível, mínimo existencial e direito à saúde: algumas aproximações. In: Direitos fundamentais: orçamento e reserva do possível. Ingo Wolfgang Sarlet; Luciano Beneti Timm (Orgs). 2ed. Porto Alegre: Livraria do Advogado. 2010.

, Ingo Wolfgang. A eficácia dos direitos fundamentais: uma teoria geral dos direitos fundamentais na perspectiva constitucional. 10 ed. Porto Alegre: Livraria do Advogado, 2010.

TIMM, Luciano Benetti. Qual a maneira mais eficiente de prover direitos fundamentais: uma perspectiva de direito e economia. In: Direitos fundamentais: orçamento e reserva do possível. Ingo Wolfgang Sarlet; Luciano Beneti Timm (Orgs). 2ed. Porto Alegre: Livraria do Advogado. 2010.

TORRES, Ricardo Lobo. 0 direito ao mínimo existencial. Rio de Janeiro: Renovar. 2010.

Recebido para publicação: 20/04/2012

Aceito para publicação: 19/12/2012 